\title{
High Pretreatment Systemic Immune-Inflammation Index Values are Associated with Diminished Short- term Success After Temporomandibular Joint Arthrocentesis Procedure
}

\author{
EFSUN SOMAY ( $\nabla$ efsuner@gmail.com ) \\ Başkent University Dentistry Faculty \\ BUSRA YILMAZ \\ Başkent University Dentistry Faculty
}

\section{Research Article}

Keywords: temporomandibular joint arthrocentesis, systemic immune-inflammation index, temporomandibular joint disorder, biomarker, success

Posted Date: August 18th, 2021

DOl: https://doi.org/10.21203/rs.3.rs-788109/v1

License: (c) (1) This work is licensed under a Creative Commons Attribution 4.0 International License. Read Full License 


\section{Abstract \\ Background}

To retrospectively assess the significance of the pretreatment systemic immune-inflammation index (SII) in predicting the success of temporomandibular joint arthrocentesis (TMJA) at 1-week, 1- month, and 6month time points.

\section{Methods}

A sum of 136 patients with disc displacement without reduction (DDwo-red) who underwent TMJA was included. For each patient, pre-TMJA SII was calculated as; SII = Platelets $\times$ neutrophils/lymphocytes. The success criteria of TMJA included MMO $>35 \mathrm{~mm}$ and VAS $\leq 3$. The optimal pre-TMJA SIl cutoff that predicts TMJA success was determined using receiver operating characteristic (ROC) curve analysis. The primary endpoint was the link between the pre-treatment SII and TMJA success.

\section{Results}

The median pre-TMJA jaw locking duration, maximum mouth opening (MMO), and visual analog score (VAS) were 7 days, $24 \mathrm{~mm}$, and 8, respectively. The overall TMJA success rates were determined as $80.1 \%, 91.9 \%$, and $69.1 \%$ at 1 -week, 1 -month, and 6-months, respectively. The results of ROC curve analysis exhibited the optimal SII cutoff at 526 (AUC:67.4\%; sensitivity:66.7\%; specificity:64.2\%) that grouped the patients into two subgroups: Group 1: $\mathrm{SII} \leq 526(\mathrm{~N}=81)$ and $\mathrm{SII}>526(\mathrm{~N}=55)$, respectively. Spearman correlation analysis revealed a strong inverse relationship between the pretreatment SII values and the success of TMJA 1-week $\left(r_{s}:-0.83 ; P=0.008\right)$ and 1-month, $\left(r_{s}:-0.89 ; p=0.03\right)$. Comparative analyses displayed that TMJA success rates at 1 -week $(87.7 \%$ versus $69.1 \% ; P=0.008)$ and 1 -month $(96.2 \%$ versus $80 \% ; p=0.03$ ) were significantly higher in the SII $\leq 526$ than SII > 526 group, respectively, while the 6-month results favored the SII $\leq 526$ group with a trend approaching significance $(p=0.084)$.

\section{Conclusion}

The current study's findings suggested the SII as a unique independent prognostic biomarker that accurately predicts treatment outcomes for up to 6 months.

\section{Trial registration:}

The results of this research were retrospectively registered.

\section{Background}


Temporomandibular joint disorders (TMD) are a diverse group of diseases affecting the temporomandibular joint (TMJ), masticatory muscles, and related structures with an overall prevalence rate of $5-12 \%$ in the general population $[1,2]$. Severe pre-auricular and masticatory area pain, joint sounds, and diminished mouth opening capacity embodies the most frequent TMD-related presenting symptoms [3]. Disc displacement with (DDw-red) or without reduction (DDwo-red) is considered to be the most certain intraarticular reason for TMD which may cause severe joint degeneration, with resultant sharp decline in quality of life measures related to persistent chronic pain, impaired eating functions, limitation of normal jaw activities, difficulty falling asleep, and resulting fatigue in DDwo-red patients [2, 4].

TMJ arthrocentesis (TMJA), with its $70-90 \%$ long-term success rate, is a relatively easy to perform and highly feasible minimally invasive procedure that efficiently reduces the complaints of DDwo-red patients who are resistant to conservative treatments (self-care measures, occlusal splint, and physical therapy) and drugs $[5,6]$. However, literature related to the short-term success of TMJA is scant [7]. The reported prognostic factors for the TMJA procedure usually refer to the patient's age, disease duration, pain severity, maximum mouth opening (MMO) capacity, and the presence of degenerative changes in the magnetic resonance imaging (MRI) scans. But sadly, emphasizing the compelling need for the identification of novel reliable prognosticators, accessible research results are often conflicting [8].

Another implied cause of TMD is local and chronic systemic inflammation, which manifests with the secretion of various biomarkers in the TMJ synovium, such as cytokines and growth factors [9]. Therefore, TMJA procedure is commonly used to defeat this inflammatory load in the joint cavity, while this procedure additionally promotes disc repair and repositioning by removing the fibrous tissues in DDwo-red patients $[5,6]$. In this sense, it is of interest to identify TMD-specific inflammatory cytokines and develop specific treatments for this particular region [8]. For this purpose, Somay and Araz and Kaneyama et al investigated the influence of pro-inflammatory cytokines and their values in synovial fluid on the success of TMJA, and declared that some inflammation and inflammatory mediators were extremely high in the synovial fluid, which meaningfully impacted the TMJA success rates $[10,11]$.

SII (Systemic Immune-Inflammation Index), a unique measure of the platelet, neutrophil, and lymphocyte counts, is a biomarker that mirrors the harmony between the patient's inflammatory and immune status, irrespective of the underlying cause [12]. SII has recently been reported to be effective in predicting the prognosis of many diseases, including osteoporosis, osteoporotic bone fractures, psoriatic arthritis, and Bell's palsy [13-15]. Nevertheless, to the best of our knowledge, SII has never been studied for its actual impact on the success of TMJA procedure. Consequently, we proposed that the pretreatment SII may also be of prognostic significance on the short-term success of the TMJA procedure by considering the inflammation, a leading cause of DDwo-red, together with the primary goal of the TMJA procedure: removal of the fibrotic tissues and inflammatory debris.

\section{Materials And Methods}




\section{Ethical approval}

The present retrospective study was designed, authorized and approved by the institutional review board of Baskent University Medical Faculty (Project no: D-KA19/19) before the compilation of any persistent data, according to the Declaration of Helsinki. The eligible patients provided signed informed consent before the initiation of all dental and medical procedures either themselves or legitimately charged caregivers for acquisition and analysis of the patients' sociodemographic, dental, and medical records; blood samples, MRI scans, and publication of the outcomes. The results of this research were retrospectively registered and evaluated.

\section{Study population}

We conducted a retrospective search of clinical, medical, and radiological records (MRI, Magnetron "Harmony" Siemens, Erlangen, Germany) maintained by the Baskent University Adana Research and Practice Center Dentistry Clinic to identify $\geq 18$ years old patients who underwent TMJA for TMD between September 2018 and July 2020. The Diagnostic Criteria for Temporomandibular Joint Disorders (DC/TMD) were used to determine the absence/presence of TMD $[2,16]$. To be eligible, all patients had to have a diagnosis of DDwo-red according to these criteria and available pre-TMJA complete blood count tests. Patients presenting with TMJ pain who had failed two months of conservative treatment (self-care preventions, occlusal splints, physical therapy, and medications) were included. Exclusion criteria comprised the presence of either of the muscle-related pains, rheumatologic diseases, TMJ ankylosis, previous TMJ surgery, history of trauma, and missing natural upper and/or lower central incisors. Patient complaints, like the presence of pain, restricted mouth opening, masticatory muscle tenderness, jaw deviation during mouth opening, bruxism, were all noted, and also the types of diagnosis indicated by MRI examination were grouped. The jaw locking duration was measured for each patient with limited mouth opening was also recorded, which was defined as the interim delaying the mouth opening and prohibiting eating functions according to the Mandibular Function Impairment Questionnaire [17]. All patients received conservative medications and physical therapy as a norm before the TMJA procedure, with TMJA being offered only for resistant cases.

\section{Preoperative assessments}

For each eligible patient, the age, gender, presence of bruxism, jaw deviation during mouth opening, and muscle tenderness were noted before the TMJA procedure. Bruxism was diagnosed when the patient had a history of tooth clenching and grinding occurring $\geq 3$ nights per week at the past 6-months [18], the experience of morning stiffness, presence of tooth wear [19], and also the appearance of linea alba in the cheek [20].

The preoperative clinical evaluations incorporated the pain assessments with the Visual Analog Scale (VAS) [21] and MMO measurements. The MMO was measured preoperatively and periodically after the TMJA procedure, 1-week, 1-month, and 6-months, respectively. The VAS test was performed at the same interims as the MMO measurements. The 6-month outcomes were particularly procured to assess the 
short-term effectiveness of the TMJA procedure. The procedure was granted to be successful if the MMO increased to $>35 \mathrm{~mm}$ and the VAS reduced to $\leq 3$, individually [5]. Patients with a pre-TMJA VAS value of $\geq 4$ were included in the present study.

\section{Measurement of maximum mouth opening (MMO)}

We used the Therabite ${ }^{\circledR}$ (Atos Medical AB, Hörby, Sweden) range of motion scale to measure MMOs, as it enables easy and direct measurement and reduced risk for procedure-related infection risk due to its disposable characteristic [22].Patients were asked to open their mouth as wide as possible, and the Therabite ${ }^{\circledR}$ range of motion scale was placed in their mouth to measure the distance between the upper borders of one of the lower central incisors to the inferior border of one of the upper central incisors during the MMO measurements. MMO measurements were repeated 3 times per session, and the mean $\mathrm{MMO}$ was determined by the calculated average of the three consecutive measurements performed by an experienced oral and maxillofacial surgeon (ES).

\section{Arthrocentesis procedure}

All patients underwent a single-session TMJA procedure performed by the same oral and maxillofacial surgeon (ES). After measuring the patient's $\mathrm{MMO}$, the preauricular skin and ear regions were prepared by cleaning with a topical antiseptic solution (Povidone-lodine $10 \% \mathrm{w} / \mathrm{v}$ ), and the surgical area was confined with a sterile cover. To block the auriculotemporal nerve, we applied 1-2 $\mathrm{mL}$ of a local anesthetic solution [Ultracain ${ }^{\circledR}$ DS Forte 40 mg/ml articaine HCL, 0.0012 mg/ml epinephrine (Sanofi-Aventis, Frankfurt, Germany)] over the preauricular region and into the superior joint space (SJS). As previously described by Nitzan et al, a line was drawn from the most posterior and central point on the tragus to the lateral canthus of the eye by a sterile skin pen [5]. The first entry point was marked 10-mm anterior of the tragus and 2-mm below this line, while the second entry point was $20-\mathrm{mm}$ anterior and 8- $\mathrm{mm}$ below this line. Then, a 21-gauge needle was inserted into the SJS at the glenoid fossa through the first point, and approximately 2-3 $\mathrm{mL}$ of Ringer's solution was pumped ten times to expand the SJS. A second 20-gauge needle was then inserted from the second entry point to enable the free flow of the irrigation solution in the SJS. Lavaging with free outflow under high pressure and with a minimum of $400 \mathrm{ml}$ Ringer's solution was considered regarded as effective irrigation [5,23]. All patients were advised for a soft diet, hot pad application, and passive stretching exercises for a week following surgery. Analgesics and myorelaxants were prescribed as needed. We standardly prescribed an occlusal splint for at least one month following surgery to prevent bruxism and associated problems.

\section{Systemic immune-inflammation index (SII) assessment}

We ran Hu's original equation to calculate the pre-TMJA SII values for each patient: SII = [Platelets $x$ (Neutrophils/Lymphocytes)], by using the routine complete blood count tests performed on the TMJA day [24]. 


\section{Statistical analysis}

The primary endpoint was the connection between the pretreatment SII values and the TMJA success. Medians and ranges were calculated to describe continuous variables, while categorical variables were expressed with percentage frequency distributions. Chi-square test, Student's t-test, or Spearman correlation analyses and related $r_{\mathrm{s}}$ values were employed to compare the patient groups, as indicated. Receiver operating characteristic (ROC) curve analysis was employed to define ideal cutoff(s) that may group the whole study into two distinctive outcome groups, such as the pre-TMJA SII measures. All comparisons were two-tailed, and any P-value $<0.05$ was considered significant.

\section{Results}

Our retrospective database search yielded a sum of 136 patients who had underwent TMJA procedure. As summarized in Table 1, the median age was 34 years (range: 18-59), with a female predominance (77.9\%). Pain (47.8\%) and difficulty in mouth opening (33.1\%) accounted for the majority $(80.9 \%)$ of the presenting complaints. The median jaw locking duration, pre-TMJA MMO, pre-TMJA VAS were 7 days [95\% confidence interval (Cl): 2.8-14 days], $24 \mathrm{~mm}$ (95\% Cl: 17.8-28.4 mm), and 8 (95\% Cl: 6.7-8.7), respectively. Presenting patient and TMD characteristics including the muscle tenderness, deviation during mouth opening, and bruxism were as shown in Table 1 . Of note, $50.7 \%$ of patients had bilateral DDwo-red (Table 1).

Overall, we found that the 1-week, 1-month, and 6-month TMJA success rates were $80.1 \%$ at, $91.9 \%$ at 1month, and $69.1 \%$, respectively, per success criteria defined as MMO> $35 \mathrm{~mm}$ and VAS $\leq 3$ (Figure 1). We used ROC curve analysis to reveal the possible connections between the pre-treatment SIl levels and TMJA success at 1-week, 1-month, and 6-month intervals. The ROC curve analysis results exhibited the optimal cutoff value at 526 (Area under the curve (AUC): 67.4\%; sensitivity: 66.7\%; and specificity: 64.2\%) for 1-week, 527 (AUC: 66.2\%; sensitivity: 65.8\%; and specificity: 64.0\%), and 524 (AUC: 65.1\%; sensitivity: $64.3 \%$; and specificity: $64.1 \%$ ) for 6 -months, respectively. Since the three cutoff values were so close, we utilized the 526 point as the common cutoff to separate patients into two groups for all time-dependent TMJA success evaluations (Figure 2): Group 1: SII $\leq 526(\mathrm{~N}=81)$ and $\mathrm{SII}>526(\mathrm{~N}=55)$, respectively. Spearman correlation analysis revealed a strong and significant inverse relationship between the pretreatment SII values and the TMJA success at 1-week and 1-month $\left(r_{\mathrm{s}}:-0.83: p=0.008, \mathrm{r}_{\mathrm{s}}:-0.89: p=0.03\right)$, with an additional trend favoring the $S I I \leq 526$ group for the TMJA success at 6 -month $\left(r_{s}=-0.42\right.$; $p=0.086$ ) evaluations (Table 2). As shown in Table 2, our comparative analyses displayed that the rates of TMJA success for 1 -week ( $87.7 \%$ versus $69.1 \% ; p=0.008$ ) and 1 -month $(96.2 \%$ versus $80 \% ; p=0.03$ ) were significantly higher in the SII $\leq 526$ group than its SIl> 526 counterparts, respectively. Although the difference between the success rates of the two SII groups could not reach statistical significance at 6months evaluations, we observed a strong trend approaching statistical significance favoring the SII $\leq$ 526 over the $\mathrm{SIl}>526$ group ( $74.1 \%$ versus $60 \%$; $\mathrm{P}=0.084$ ). 
We further sought for the presence of additional relevant cutoff(s) for other covariates which may alter the TMJA success rates significantly in favor of one group (Table 3). Our search with ROC curve analysis revealed a significant cutoff uniquely for the jaw locking duration at a threshold of 7.5 days (AUC: $72.2 \%$ sensitivity: 74.1\%; and specificity: 66.1\%) (Figure 3). Comparative analyses displayed that the rates of TMJA success were significantly higher in patients presenting with a jaw locking duration $<8$ days at 1 week ( $66 \%$ versus $34 \% ; p<0.001)$, 1 -month $(61.5 \%$ versus $38.5 \%$; $p=0.003)$, and 6 -month $(74.2 \%$ versus $25.8 \% ; p<0.001)$ group than their $\geq 8$ days counterparts.

\section{Discussion}

The current retrospective research found that the pre-TMJA SII> 526 strongly and independently link with significantly lower 1-week $(p=0.008)$ and 1 -month $(p=0.03)$ TMJA success rates, with an additional trend approaching significance at 6 -months $(p=0.084)$ success rate, as well. Furthermore, the longer jaw locking duration ( $\geq 8$ days; $p=0.01, p=0.023$, and $p=0.001$ ) were discovered to have negative impacts on the short-term TMJA success.

The local inflammation of DD is caused by an inflammatory process on the TMJ joint surface and synovial fluid [25]. McCain discovered that synovial hypervascularity was more common and coexisted with exacerbated local inflammation in DDwo-red TMJ patients than in DDw-red TMJ patients [26]. Likewise, Nitzan et al. and Murakami et al. found that the impotence of the condyle to slide during regular mouth opening was linked to inflammatory alterations on the joint surface $[5,27]$. Although the precise mechanisms attaching local and systemic inflammation in TMD have yet to be determined, TMD cartilage degeneration has been reported to be caused by expanded local inflammation in individuals with systemic inflammatory diseases such as osteoarthritis, as evidenced by the presence of elevated levels of pro-inflammatory and inflammatory mediators in the TMJ joint space [9]. Because circulating pro-inflammatory mediators such as TNF- $a$ and IL-6 have been shown to influence TMJA success $[9,28,29]$, it is prudent to assume that other systemic biomarkers, such as the SII, could also be relevant in predicting TMJA outcomes, given that local inflammation invokes systemic inflammation.

The primary discovery of this study was the demonstration of the SIl as a novel indicator for TMJA success, in addition to its known prognostic efficacy in a large variety of diseases [30-32]. Despite the apparent lack of previous results to objectively compare these first outcomes, we can still propose some insightful hypotheses by considering the critical actions of local and systemic inflammation on the success of TMJA, which is exhibited by the immune and inflammatory cell components of the unique SII formula: platelets (PLTs), neutrophils, and lymphocytes. Increased peripheral blood PLT count is considered a powerful indicator of the state of the continuously rising systemic inflammatory response, which can promote occlusion of small blood vessels with subsequent bony ischemia in the jawbones [33]. Neutrophils are the most numerous immune cells in the oral cavity, which assume vital roles in local/systemic immunity and inflammation with their phagocytotic, and reactive oxygen species plus cytokine/chemokine manufacturing and secreting functions [34]. Unlike the inflammatory neutrophils, lymphocytes are immune cells that migrate to the injured region to fight against the causes 
of inflammation [35]. Hence, as a result of elevated neutrophil and PLT numbers and reduced lymphocyte counts, enhanced systemic inflammation results in a high SII score. Although investigations that directly address this issue are needed, the lower TMJA success rates at all time points in the high SIl group may be related to persistent systemic inflammation in this particular patient gathering.

We uncovered an influential link between high pre-TMJA SII values and short-term success of TMJA procedure, especially at 1-week and 1-month, with an extra trend approaching significance at 6-months. This latter result, however, might be attributed to the limited sample size. Furthermore, because SII lost its predictive relevance at 6-months, we assume that the effect of pre-TMJA SII on the success of the procedure was reduced as a result of the time-dependent resolution of the local inflammation. Given these results it is possible that the TMJA treatment might have totally cleared, or at least significantly reduced, the local inflammation and its systemic extension in less than six months of the procedure.

Former research has proposed jaw locking duration as a notable predictor of TMJA success in DDwo-red patients $[5,35,36]$. We likewise distinguished the jaw locking duration as a significant indicator of TMJA success at 1-week, 1-month, and 6-month evaluations. In support, Kaneyama et al proclaimed that the longer jaw locking durations were associated with the presence of severe synovial inflammation and reduced TMJA success rates [11]. Although the time cutoff of 1-month in Sembronio and colleagues' study was remarkably longer than our 7-days, the authors reported that the longer jaw locking duration was linked to a significantly reduced TMJA success rate $(87.5 \%$ versus $68.0 \%$ for $>1$-month; $P)$ at 1 year [37]. Although the precise causes are unknown, it is reasonable to deduce that the inflamed synovium and associated local and/or systemic inflammatory mediators may have prolonged jaw locking durations, resulting in decreased TMJA success [29].

The overall success rates of the TMJA procedure for TMDs typically range from $70 \%$ to $91.9 \%$ depending on the post-procedural assessment periods $[5,38,39]$. Although the patients were not urged for scheduled interim controls, Nitzan et al. reported their success rates between $91 \%$ and $95 \%$ at a follow-up of 4 to 14 months, which is the highest of any TMJA success rates ever recorded [5]. On the other hand, Murakami [38] and Hosaka [39] reported respective $70 \%$ and $79 \%$ success rates at the 6-month evaluations, where our $69.1 \%$ success rate at 6 -month appears to be almost equal to Murakami's $70 \%$. Although the observation that the $91.9 \%$ success rate at 1 -month was reduced to $69.1 \%$ herein and to $70 \%$ in Murakami's study at 6-months of the TMJA procedure, they altogether suggest that the procedural success was declining in a time-dependent manner [38]. However, signifying the TMJA as a feasible treatment option for refractory TMDs, our $69.1 \%$ success rate at 6 -months is still superior over a rate of $55.9 \%$ reported for conservative therapies in a recent meta-analysis [40].

The present research is handicapped with several shortcomings. First, because they apply only to single institutional retrospective research with a relatively small cohort size, the observed results should be regarded as just hypothesis-generating. Second, even though the SII was a dynamic systemic biomarker with significant time-dependent variations, our SII measurements were based on a single time-point estimation acquired immediately before the TMJA treatment. Third, we may have lost an opportunity to 
uncover the complicated processes behind the link between a higher SIl value and lower TMJA success rates since we did not assess additional inflammatory markers such as TNF- $-\mathrm{a}, \mathrm{IL}-6$, and many others. As a result, future studies focusing on these key concerns may give helpful information regarding the real influence of pre-treatment SII values on the TMJA results of TMD patients.

\section{Abbreviations}

SII (Systemic Immune-Inflammation Index);Temporomandibular joint disorders (TMD); Temporomandibular joint (TMJ); TMJ arthrocentesis (TMJA); Disc displacement with (DDw-red); Disc displacement without reduction (DDwo-red); Maximum mouth opening (MMO); magnetic resonance imaging (MRI); The Diagnostic Criteria for Temporomandibular Joint Disorders (DC/TMD); Visual Analog Scale (VAS); superior joint space (SJS); Receiver operating characteristic (ROC); Area under the curve (AUC); confidence interval (Cl): platelets (PLTs).

\section{Declarations}

\section{Ethics, consent and permission}

Before acquiring any information from the patient, the study design has been approved by the Institutional Review Board of the Baskent University School of Medicine and has been in compliance with the Declaration of Helsinki. We ensured that all patients signed an informed consent form before the beginning of the evaluation, either themselves or their legally authorized representatives for acquisition and analysis of the patients' sociodemographic, dental, and medical records; blood samples, MRI scans, and publication of the outcomes.

\section{Consent of publication}

Not applicable

\section{Availability of Data and metarials}

Data cannot be shared publicly because the data is owned and saved by Baskent University Medical Faculty. Data are available from the Baskent University Institutional Data Access / Ethics Committee (contact via Baskent University Ethics Committee) for researchers who meet the criteria for access to confidential data: contact address, adanabaskent@baskent.edu.tr.

\section{Competing interests}

The authors have declared that no competing interests exist. 


\section{Funding}

The authors declare that they have not received any financial support.

\section{Author Contributions}

ES performed TMJA for all patients; ES and BY conceived the study, participated in the study's design, and performed clinical examination and statistical analysis. All authors contributed significantly and equall, and all authors approved the final form of the manuscript.

\section{Acknowledgments}

Special thanks to Professor Erkan Topkan (Department of Radiation Oncology).

\section{Author Details}

${ }^{1}$ Department of Oral and Maxillofacial Surgery, Faculty of Dentistry, Baskent University, Ankara, Turkey.

${ }^{2}$ Department of Dentomaxillofacial Radiology, Faculty of Dentistry, Baskent University, Ankara, Turkey.

\section{References}

1. Somay E, Yilmaz B. Comparison of clinical and magnetic resonance imagining data of patients with temporomandibular disorders. Niger J Clin Pract. 2020;23:376-80.

2. Schiffman E, Ohrbach R, Truelove $E$, et al. International RDC/TMD Consortium Network, International association for Dental Research; Orofacial Pain Special Interest Group, International Association for the Study of Pain: Diagnostic Criteria for Temporomandibular Disorders (DC/TMD) for Clinical and Research Applications: recommendations of the International RDC/TMD Consortium Network and Orofacial Pain Special Interest Group. J Oral Facial Pain Headache. 2014;28:6-27.

3. Nassif NJ, Al-Salleeh F, Al-Admawi M. The prevalence and treatment needs of symptoms and signs of temporomandibular disorders among young adult males. J Oral Rehabil. 2003;30:944-50.

4. Ahmad M, Schiffman EL. Temporomandibular Joint Disorders and Orofacial Pain. Dent Clin North Am. 2016;60:105-24.

5. Nitzan DW, Dolwick MF, Martinez GA. Temporomandibular joint arthrocentesis: a simplified treatment for severe, limited mouth opening. J Oral Maxillofac Surg. 1991;49:1163-67.

6. Milam SB, Schmitz JP. Molecular biology of temporomandibular joint disorders: proposed mechanisms of disease. J Oral Maxillofac Surg. 1995;53:1448-54.

7. Bouloux GF, Chou J, Krishnan D, et al. Is Hyaluronic Acid or Corticosteroid Superior to Lactated Ringer Solution in the Short Term for Improving Function and Quality of Life After Arthrocentesis? Part 2. J 
Oral Maxillofac Surg. 2017;75:63-72.

8. Ibi M. Inflammation and Temporomandibular Joint Derangement. Biol Pharm Bull. 2019;42:538-42.

9. Cevidanes LH, Walker D, Schilling J, et al. 3D osteoarthritic changes in TMJ condylar morphology correlates with specific systemic and local biomarkers of disease. Osteoarthritis Cartilage. 2014;22:1657-67.

10. Somay E, Araz K. The Evaluation of sIL-1RII, sTNF-aRI and sIL-6R Concentrations in Synovial Fluid in Patients with Temporomandibular Joint Derangements and affects on Success of Arthrocentesis. International Journal of Science and Research. 2019;8:670-73.

11. Kaneyama K, Segami N, Sun W, Sato J, Fujimura K. Analysis of tumor necrosis factor-alpha, interleukin-6, interleukin-1 beta, soluble tumor necrosis factor receptors I and II, interleukin-6 soluble receptor, interleukin-1 soluble receptor type II, interleukin-1 receptor antagonist, and protein in the synovial fluid of patients with temporomandibular joint disorders. Oral Surg Oral Med Oral Pathol Oral Radiol Endod. 2005;99:276-84.

12. Yilmaz A, Mirili C, Bilici M, Tekin SB. A novel predictor in patients with gastrointestinal stromal tumors: Systemic immune-inflammation index (SII). J BUON. 2019;24:2127-35.

13. Fang $\mathrm{H}$, Zhang $\mathrm{H}$, Wang Z, Zhou Z, Li Y, Lu L. Systemic immune-inflammation index acts as a novel diagnostic biomarker for postmenopausal osteoporosis and could predict the risk of osteoporotic fracture. J Clin Lab Anal. 2020;34:e23016.

14. Yorulmaz A, Hayran Y, Akpinar U, Yalcin B. Systemic Immune-Inflammation Index (SII) Predicts Increased Severity in Psoriasis and Psoriatic Arthritis. Curr Health Sci J. 2020;46:352-57.

15. Kinar A, Ulu S, Bucak A, Kazan E. Can Systemic Immune-Inflammation Index (SII) be a prognostic factor of Bell's palsy patients? Neurol Sci. Epub 2020 Nov 25.

16. Dworkin SF, LeResche L. Research diagnostic criteria for temporomandibular disorders: review, criteria, examinations and specifications, critique. J Craniomandib Disord. 1992;6:30155.

17. Miranda SB, Possebon APDR, Schuster AJ, Marcello-Machado RM, de Rezende Pinto L, Faot F. Relationship Between Masticatory Function Impairment and Oral Health-Related Quality of Life of Edentulous Patients: An interventional Study. J Prosthodont. 2019;28:634-42.

18. Lee R, Yeo ST, Rogers SN, et al. Randomised feasibility study to compare the use of Therabite ${ }^{\circledR}$ with wooden spatulas to relieve and prevent trismus in patients with cancer of the head and neck. $\mathrm{Br} J$ Oral Maxillofac Surg. 2018;56:283-91.

19. Kamstra JI, Roodenburg JL, Beurskens CH, Reintsema H, Dijkstra PU. TheraBite exercises to treat trismus secondary to head and neck cancer. Support Care Cancer. 2013;21:951-57.

20. American Association of Oral and Maxillofacial Surgeons. 1984 Criteria for TMJ Meniscus Surgery. Chicago: American Association of Oral and Maxillofacial Surgeons; 1984:1-40.

21. Emshoff R, Rudisch A. Temporomandibular joint internal derangement and osteoarthrosis: are effusion and bone marrow edema prognostic indicators for arthrocentesis and hydraulic distention? J Oral Maxillofac Surg. 2007;65:66-73. 
22. Bhargava D, Jain M, Deshpande A, Singh A, Jaiswal J. Temporomandibular joint arthrocentesis for internal derangement with disc displacement without reduction. J Maxillofac Oral Surg. 2015;14:454-59.

23. Kaneyama K, Segami N, Nishimura M, Sato J, Fujimura K, Yoshimura H. The ideal lavage volume for removing bradykinin, interleukin- 6 , and protein from the temporomandibular joint by arthrocentesis. $J$ Oral Maxillofac Surg. 2004;62:657-61.

24. Hu B, Yang $X R$, Xu Y, et al. Systemic immune-inflammation index predicts prognosis of patients after curative resection for hepatocellular carcinoma. Clin Cancer Res. 2014;20:6212-22.

25. Dalewski B, Kamińska A, Białkowska K, Jakubowska A, Sobolewska E. Association of Estrogen Receptor 1 and Tumor Necrosis Factor a Polymorphisms with Temporomandibular Joint Anterior Disc Displacement without Reduction. Dis Markers. 2020;2020:6351817.

26. McCain JP, de la Rua H, Le Blanc WG. Correlation of clinical, radiographic, and arthroscopic findings in internal derangements of the TMJ. J Oral Maxillofac Surg. 1989;47:913-21.

27. Murakami KI, Lizuka T, Matsuki M, Ono T. Diagnostic arthroscopy of the TMJ: differential diagnoses in patients with limited jaw opening. Cranio. 1986;4:117-26.

28. Kristensen KD, Alstergren P, Stoustrup P, Küseler A, Herlin T, Pedersen TK. Cytokines in healthy temporomandibular joint synovial fluid. J Oral Rehabil. 2014;41:250-56.

29. Gulen H, Ataoglu H, Haliloglu S, Isik K. Proinflammatory cytokines in temporomandibular joint synovial fluid before and after arthrocentesis. Oral Surg Oral Med Oral Pathol Oral Radiol Endod. 2009;107:e1-4.

30. Singh N, Baby D, Rajguru JP, Patil PB, Thakkannavar SS, Pujari VB. Inflammation and cancer. Ann Afr Med. 2019;18:121-26.

31. Esser N, Legrand-Poels S, Piette J, Scheen AJ, Paquot N. Inflammation as a link between obesity, metabolic syndrome and type 2 diabetes. Diabetes Res Clin Pract. 2014;105:141-50.

32. Carrizales-Sepúlveda EF, Ordaz-Farías A, Vera-Pineda R, Flores-Ramírez R. Periodontal Disease, Systemic Inflammation and the Risk of Cardiovascular Disease. Heart Lung Circ. 2018;27:1327-34.

33. Medara N, Lenzo JC, Walsh KA, Reynolds EC, O'Brien-Simpson NM, Darby IB. Peripheral neutrophil phenotypes during management of periodontitis. J Periodontal Res. 2021;56(1):58-68.

34. Moore C, McLister C, Cardwell C, O'Neill C, Donnelly M, McKenna G. Dental caries following radiotherapy for head and neck cancer: A systematic review. Oral Oncol. 2020;100:104484.

35. Talaat W, Ghoneim MM, Elsholkamy M. Single-needle arthrocentesis (Shepard cannula) vs. doubleneedle arthrocentesis for treating disc displacement without reduction. Cranio. 2016;34:296-302.

36. Al-Baghdadi M, Durham J, Araujo-Soares V, Robalino S, Errington L, Steele J. TMJ Disc Displacement without Reduction Management: A Systematic Review. J Dent Res. 2014;93 (Suppl 7):S37-S51.

37. Sembronio S, Albiero AM, Toro C, Robiony M, Politi M. Is there a role for arthrocentesis in recapturing the displaced disc in patients with closed lock of the temporomandibular joint? Oral Surg Oral Med Oral Pathol Oral Radiol Endod. 2008;105:274 - 80; discussion 281. 
38. Murakami K, Hosaka H, Moriya Y, Segami N, lizuka T. Short-term treatment outcome study for the management of temporomandibular joint closed lock. A comparison of arthrocentesis to nonsurgical therapy and arthroscopic lysis and lavage. Oral Surg Oral Med Oral Pathol Oral Radiol Endod. 1995;80:253-57.

39. Hosaka H, Murakami K, Goto K, lizuka T. Outcome of arthrocentesis for temporomandibular joint with closed lock at 3 years follow-up. Oral Surg Oral Med Oral Pathol Oral Radiol Endod. 1996;82:501-04.

40. Al-Moraissi EA, Wolford LM, Ellis E 3rd, Neff A. The hierarchy of different treatments for arthrogenous temporomandibular disorders: A network meta-analysis of randomized clinical trials. J Craniomaxillofac Surg. 2020;48:9-23.

\section{Tables}


Table 1

Baseline patient and TMD characteristics

\section{Characteristics}

Median age, years (range)

Gender, N (\%)

Female

Male

Presenting complaints, $\mathrm{N}(\%)$

Pain

Difficulty in mouth opening

Both

Median jaw locking duration, day $(95 \% \mathrm{Cl})$

Median pre-TMJA MMO, mm $(95 \% \mathrm{Cl})$

Median pre-TMJA VAS $(95 \% \mathrm{Cl})$

Muscle tenderness, N (\%)

Yes

No

Deviation during mouth opening, $\mathrm{N}(\%)$

Yes

No

MRI findings, $\mathrm{N}(\%)$

Unilateral DDwo-red

Bilateral DDwo-red

Bruxism, N (\%)

Yes

No
All patients

$(\mathrm{N}=136)$

$34(18-59)$

106 (77.9)

$30(22.1)$

65 (47.8)

45 (33.1)

$26(19.1)$

$7(2.8-14)$

$24(17.8-28.4)$

8 (6.7-8.7)

27 (19.9)

$109(80.1)$

44 (32.4)

$92(67.6)$

67 (49.3)

69 (50.7)

62 (45.6)

74 (54.4)

$\mathrm{Cl}$, confidence interval; DDwo-red, disc displacement without reduction; $\mathrm{mm}$, millimeter; $\mathrm{MMO}$, maximum mouth opening; MRI, magnetic resonance imaging; TMD, temporomandibular joint disorder; TMJA, temporomandibular joint arthrocentesis; VAS, visual analog scale. 
Table 2

TMJA success for the per SIl status

\begin{tabular}{|lllll|}
\hline TMJA success & $\begin{array}{l}\text { All patients } \\
(\mathbf{N}=\mathbf{1 3 6})\end{array}$ & $\begin{array}{l}\text { SII } \leq \mathbf{5 2 6} \\
\mathbf{( N = 8 1 )}\end{array}$ & $\begin{array}{l}\text { SII > 526 } \\
\mathbf{( N = 5 5 )}\end{array}$ & P-value \\
\hline 1-week, N (\%) & $109(80.1)$ & $71(87.7)$ & $38(69.1)$ & 0.008 \\
Yes & $27(19.8)$ & $10(12.3)$ & $17(30.9)$ & \\
No & & & \\
\hline 1-month, N (\%) & $122(89.7)$ & $78(96.3)$ & $44(80.0)$ & 0.03 \\
Yes & $14(10.3)$ & $3(3.7)$ & $11(20.0)$ & \\
No & & & & \\
\hline 6-month, N (\%) & $99(72.8)$ & $60(74.1)$ & $33(60.0)$ & 0.084 \\
Yes & $43(27.2)$ & $21(25.9)$ & $22(40.0)$ & \\
No & & & \\
\hline TMJA, temporomandibular joint arthrocentesis; SII, systemic immune-inflammation index. & \\
\hline
\end{tabular}


Table 3

TMJA success per presenting patient and TMD characteristics

\begin{tabular}{|c|c|c|c|c|c|c|c|c|c|}
\hline \multirow[t]{2}{*}{ Characteristic } & \multicolumn{2}{|c|}{$\begin{array}{l}\text { TMJA success } \\
\text { 1-week }\end{array}$} & \multirow[t]{2}{*}{$\begin{array}{l}\mathrm{P}- \\
\text { value }\end{array}$} & \multicolumn{2}{|c|}{$\begin{array}{l}\text { TMJA success } \\
\text { 1-month }\end{array}$} & \multirow[t]{2}{*}{$\begin{array}{l}\mathrm{P} \text { - } \\
\text { value }\end{array}$} & \multicolumn{2}{|c|}{$\begin{array}{l}\text { TMJA success } \\
\text { 6-month }\end{array}$} & \multirow[t]{2}{*}{$\begin{array}{l}\mathrm{P} \text { - } \\
\text { value }\end{array}$} \\
\hline & Yes & No & & Yes & No & & Yes & No & \\
\hline $\begin{array}{l}\text { Muscle } \\
\text { tenderness, N (\%) }\end{array}$ & $\begin{array}{l}24 \\
(22.0)\end{array}$ & $\begin{array}{l}3 \\
(11.1)\end{array}$ & 0.28 & $\begin{array}{l}25 \\
(20.5)\end{array}$ & $\begin{array}{l}2 \\
(14.3)\end{array}$ & 0.74 & $\begin{array}{l}16 \\
(17.2)\end{array}$ & $\begin{array}{l}11 \\
(25.6)\end{array}$ & 0.26 \\
\hline $\begin{array}{l}\text { Yes } \\
\text { No }\end{array}$ & $\begin{array}{l}85 \\
(78.0)\end{array}$ & $\begin{array}{l}24 \\
(88.9)\end{array}$ & & $\begin{array}{l}97 \\
(79.5)\end{array}$ & $\begin{array}{l}12 \\
(85.7)\end{array}$ & & $\begin{array}{l}77 \\
(82.8)\end{array}$ & $\begin{array}{l}32 \\
(74.4)\end{array}$ & \\
\hline \multirow{2}{*}{$\begin{array}{l}\text { Jaw deviation } \\
\text { during mouth } \\
\text { opening, N (\%) } \\
\text { Yes }\end{array}$} & $\begin{array}{l}34 \\
(31.2)\end{array}$ & $\begin{array}{l}10 \\
(37.0)\end{array}$ & 0.65 & $\begin{array}{l}39 \\
(32.0)\end{array}$ & $\begin{array}{l}5 \\
(35.7)\end{array}$ & 0.77 & $\begin{array}{l}26 \\
(28.0)\end{array}$ & $\begin{array}{l}18 \\
(41.9)\end{array}$ & 0.12 \\
\hline & $\begin{array}{l}75 \\
(68.8)\end{array}$ & $\begin{array}{l}17 \\
(63.0)\end{array}$ & & $\begin{array}{l}83 \\
(68.0)\end{array}$ & $\begin{array}{l}9 \\
(64.3)\end{array}$ & & $\begin{array}{l}67 \\
(72.0)\end{array}$ & $\begin{array}{l}25 \\
(58.1)\end{array}$ & \\
\hline \multicolumn{10}{|l|}{ No } \\
\hline $\begin{array}{l}\text { Types of MRI } \\
\text { findings, N (\%) }\end{array}$ & $\begin{array}{l}51 \\
(46.8)\end{array}$ & $\begin{array}{l}16 \\
(59.3)\end{array}$ & 0.27 & $\begin{array}{l}60 \\
(49.2)\end{array}$ & $\begin{array}{l}7 \\
(50.0)\end{array}$ & 0.66 & $\begin{array}{l}45 \\
(48.4)\end{array}$ & $\begin{array}{l}22 \\
(51.2)\end{array}$ & 0.86 \\
\hline $\begin{array}{l}\text { Unilateral DDwo- } \\
\text { red }\end{array}$ & $\begin{array}{l}58 \\
(53.2)\end{array}$ & $\begin{array}{l}11 \\
(40.7)\end{array}$ & & $\begin{array}{l}62 \\
(50.8)\end{array}$ & $\begin{array}{l}7 \\
(50.0)\end{array}$ & & $\begin{array}{l}48 \\
(51.6)\end{array}$ & $\begin{array}{l}21 \\
(48.8)\end{array}$ & \\
\hline \multicolumn{10}{|l|}{$\begin{array}{l}\text { Bilateral DDwo- } \\
\text { red }\end{array}$} \\
\hline Bruxism, N (\%) & $\begin{array}{l}53 \\
(48.6)\end{array}$ & $\begin{array}{l}9 \\
(33.3)\end{array}$ & 0.20 & $\begin{array}{l}57 \\
(46.7)\end{array}$ & $\begin{array}{l}5 \\
(35.7)\end{array}$ & 0.57 & $\begin{array}{l}44 \\
(47.3)\end{array}$ & $\begin{array}{l}18 \\
(41.9)\end{array}$ & 0.58 \\
\hline No & $\begin{array}{l}56 \\
(51.4)\end{array}$ & $\begin{array}{l}18 \\
(66.7)\end{array}$ & & $\begin{array}{l}65 \\
(53.3)\end{array}$ & $\begin{array}{l}9 \\
(64.3)\end{array}$ & & $\begin{array}{l}49 \\
(52.7)\end{array}$ & $\begin{array}{l}25 \\
(51.1)\end{array}$ & \\
\hline $\begin{array}{l}\text { Jaw locking } \\
\text { duration, } N(\%)\end{array}$ & $\begin{array}{l}37 \\
(34.0)\end{array}$ & $\begin{array}{l}20 \\
(74.1)\end{array}$ & 0.001 & $\begin{array}{l}47 \\
(38.5)\end{array}$ & $\begin{array}{l}10 \\
(71.4)\end{array}$ & 0.023 & $\begin{array}{l}24 \\
(25.8)\end{array}$ & $\begin{array}{l}33 \\
(76.7)\end{array}$ & 0.001 \\
\hline $\begin{array}{l}\geq 8 \\
<8\end{array}$ & $\begin{array}{l}72 \\
(66.0)\end{array}$ & $\begin{array}{l}7 \\
(25.9)\end{array}$ & & $\begin{array}{l}75 \\
(61.5)\end{array}$ & $\begin{array}{l}4 \\
(28.6)\end{array}$ & & $\begin{array}{l}69 \\
(74.2)\end{array}$ & $\begin{array}{l}10 \\
(23.3)\end{array}$ & \\
\hline $\begin{array}{l}\text { Median Pre-TMJA } \\
\text { MMO (mm), N (\%) }\end{array}$ & $\begin{array}{l}57 \\
(52.2)\end{array}$ & $\begin{array}{l}14 \\
(51.9)\end{array}$ & 0.98 & $\begin{array}{l}61 \\
(50.0)\end{array}$ & $\begin{array}{l}10 \\
(71.4)\end{array}$ & 0.16 & $\begin{array}{l}45 \\
(48.4)\end{array}$ & $\begin{array}{l}26 \\
(60.5)\end{array}$ & 0.20 \\
\hline $\begin{array}{l}\leq 24 \\
>24\end{array}$ & $\begin{array}{l}52 \\
(47.8)\end{array}$ & $\begin{array}{l}13 \\
(48.1)\end{array}$ & & $\begin{array}{l}61 \\
(50.0)\end{array}$ & $\begin{array}{l}4 \\
(28.6)\end{array}$ & & $\begin{array}{l}48 \\
(51.6)\end{array}$ & $\begin{array}{l}17 \\
(39.5)\end{array}$ & \\
\hline
\end{tabular}




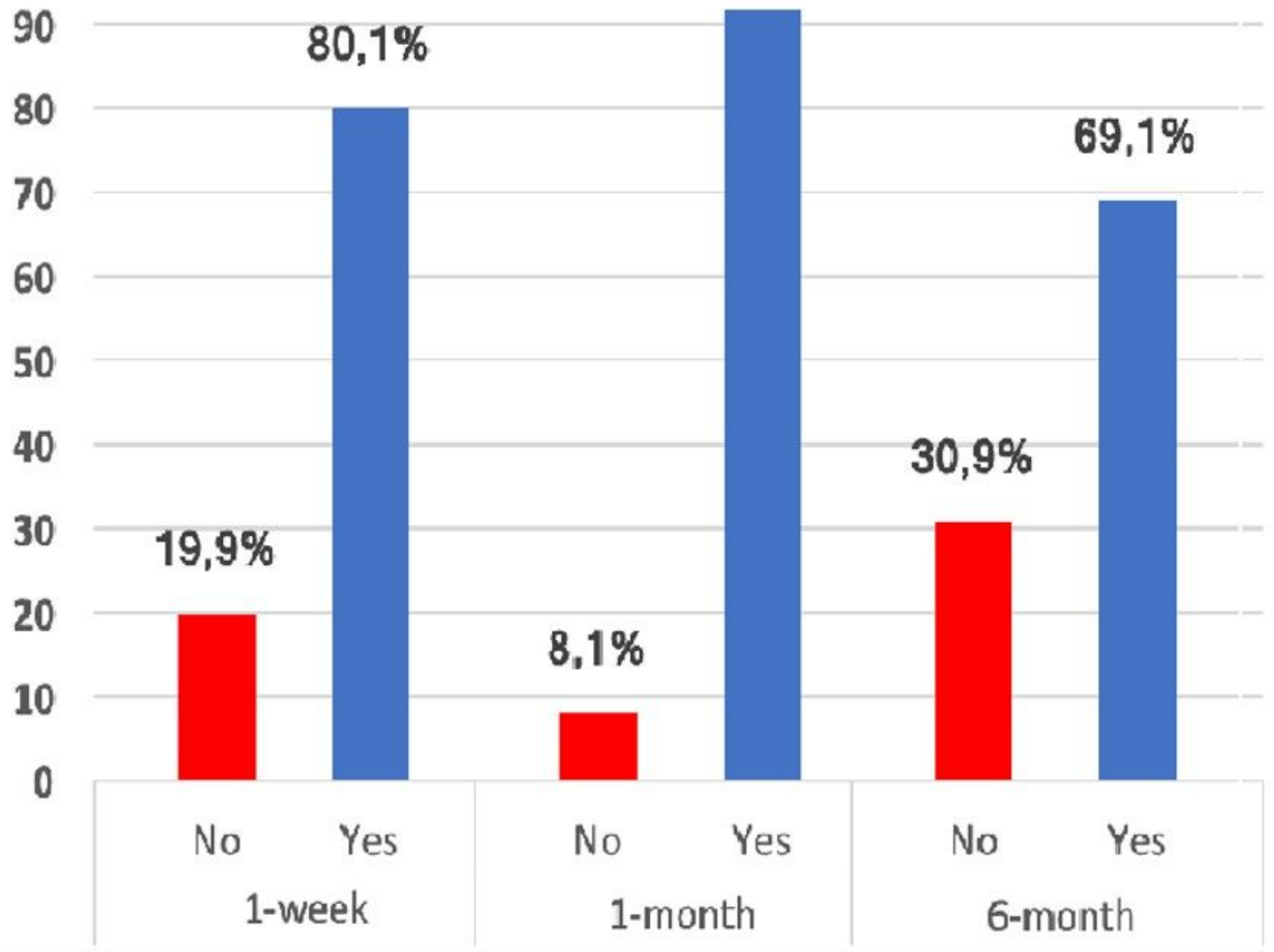

Figure 1

Overall success of TMJA at 1-week, 1-month, and 6-month. 


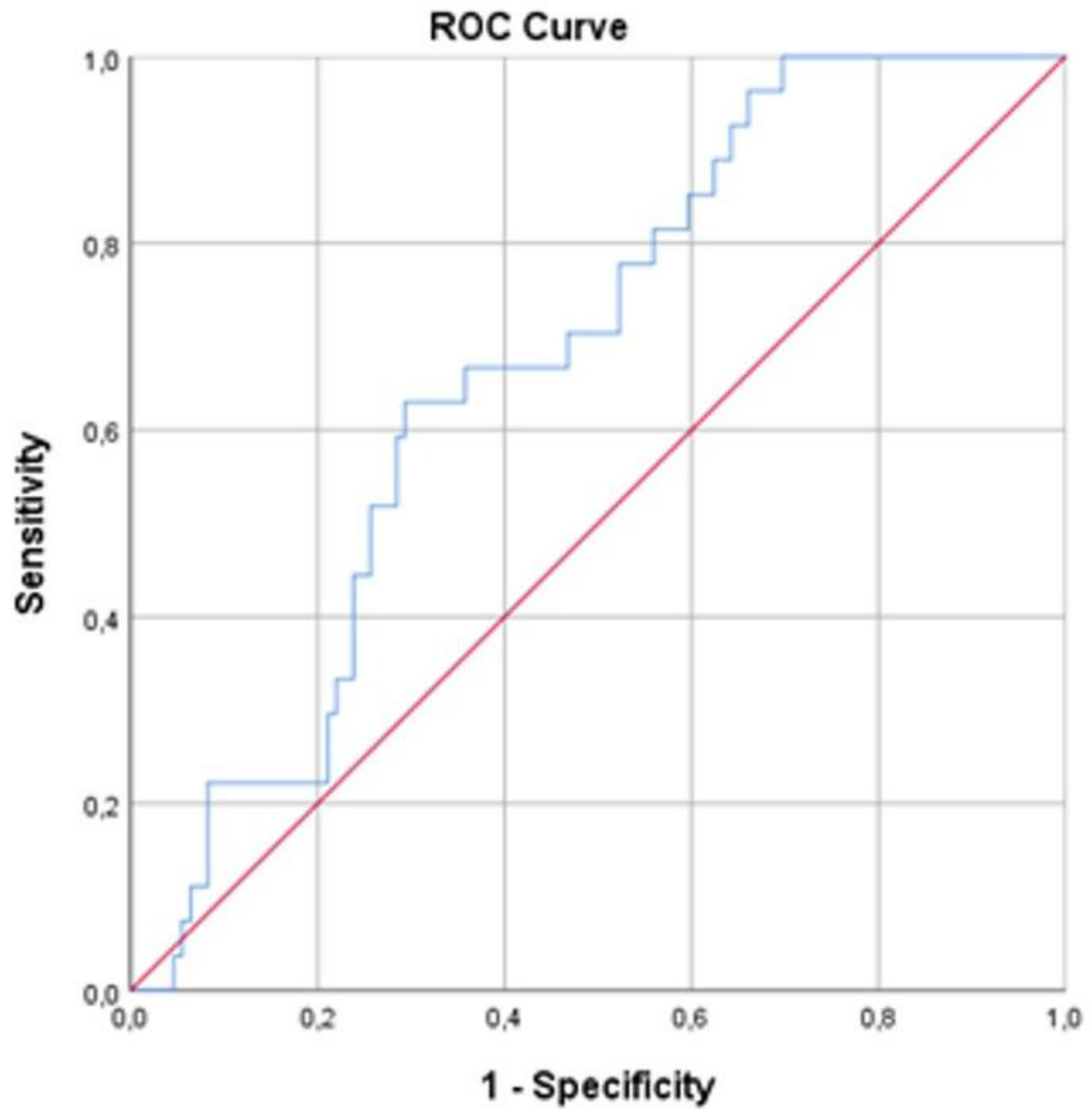

Figure 2

Results of ROC analysis evaluating the relationship between the pretreatment SII measures and TMJA success. 
ROC Curve

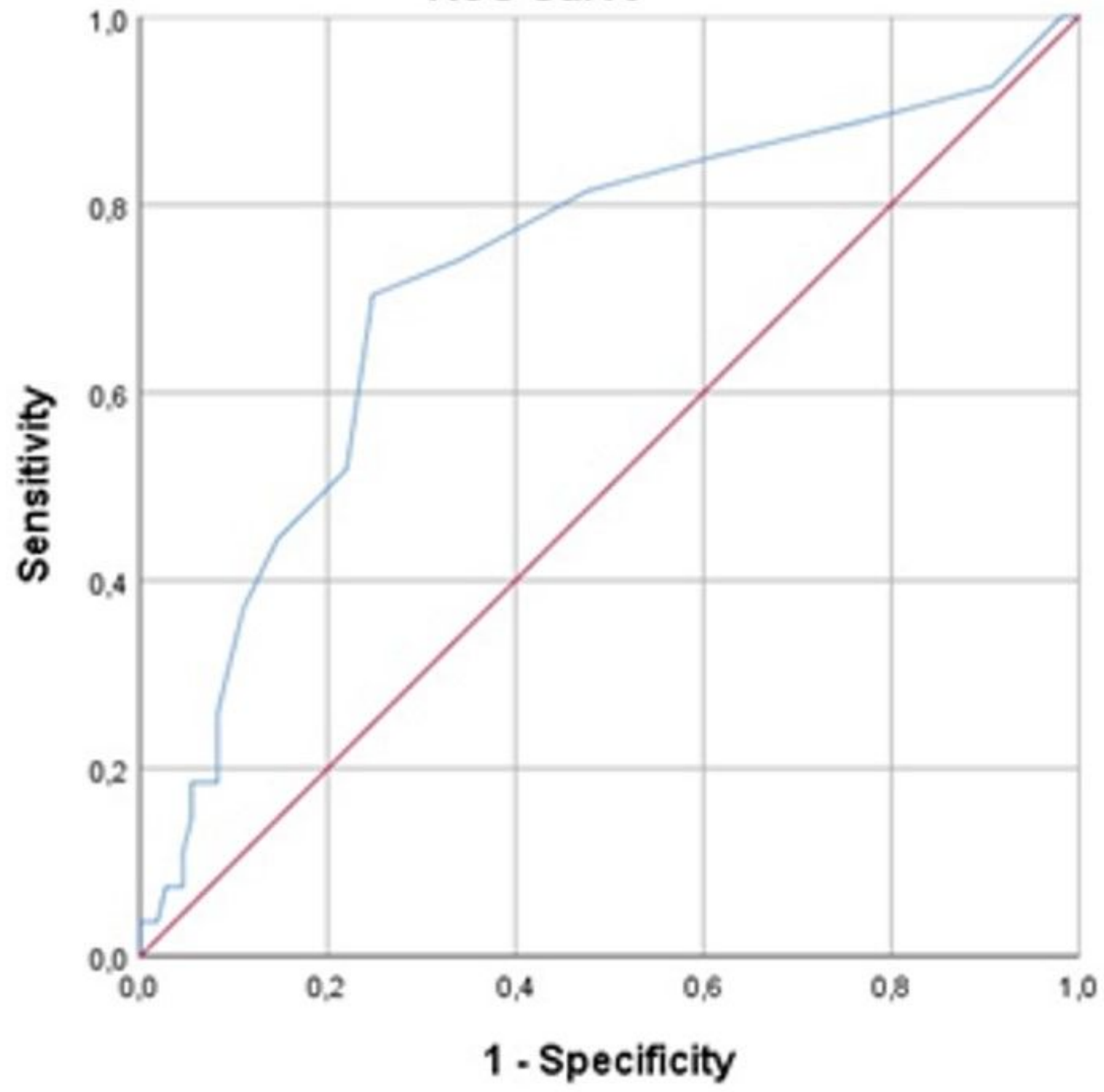

Figure 3

Results of ROC analysis evaluating the relationship between the pretreatment jaw locking duration and TMJA success. 